ECCOMAS

Proceedia

\title{
PREDICTING RAILWAY DISPLACEMENTS WITH THE HARDENING SOIL SMALL STRAIN MODEL NEAR CRITICAL SPEED
}

\author{
J. Fernández-Ruiz ${ }^{1}$ and P. Alves Costa ${ }^{2}$ \\ ${ }^{1}$ Department of Civil Engineering, University of La Coruña \\ Campus de Elviña, 15071 La Coruña (Spain) \\ e-mail: jesus.fernandez.ruiz@udc.es \\ ${ }^{2}$ CONSTRUCT, Faculty of Engineering, University of Porto, Porto, Portugal \\ R/ Dr Roberto frias, 4200-465 Porto (Portugal) \\ pacosta@fe.up.pt
}

\begin{abstract}
The prediction of railway track displacements is a topic of great interest in railway engineering. Different constitutive models of the materials (ballast, sub-ballast and ground) have been applied, from the linear elastic model to non-linear models based on the Equivalent Linear approach. In the technical literature, it is shown how non-linear models enhance the prediction of the displacements of the railway track, especially when the train's running speed approaches the critical speed. In this paper and for the first time to the authors' knowledge, the Hardening Soil Small Strain model is applied and experimentally validated to the study of track displacements near critical speed. Specifically, the well-known case at Ledsgaard (Sweden) has been used for its evaluation, showing numerical results very similar to those measured experimentally. Moreover, the critical speed is calculated, showing values significantly lower than those calculated with the linear elastic model. This is relevant for practical geotechnical engineers, even assuming a certain complexity of the model, because its use is increasingly widespread in commercial finite element codes.
\end{abstract}

Keywords: Critical speed, Non-linear soil behaviour, Railway geotechnics, Soil dynamics, Numerical modelling

ISSN:2623-3347 (C) 2021 The Authors. Published by Eccomas Proceedia.

Peer-review under responsibility of the organizing committee of COMPDYN 2021.

doi: 10.7712/120121.8476.19393 


\section{INTRODUCTION}

The study and conceptualization of the phenomenon of critical speed in railway lines have been developed since the 1990s, after the problems arising from the increase in the speed of train operation following the rehabilitation of the railway line in Ledsgard [1-4]. This increase in speed led to a considerable increase in the track displacements.

From a theoretical point of view, the critical speed is the speed of a non-oscillating moving load that implies the greatest amplification of the dynamic response. It is the properties of wave propagation in the embankment-ground system and the bending wave propagation in the track that completely determine this phenomenon [5-8]. This is associated with a considerable increase in ground deformations, which may even be permanent [9-10], which can be of great importance in high-speed lines [11-12] and be critical in soft soils.

When a train travels at lower speeds and speeds far from those of Rayleigh wave propagation on the ground, the level of strains induced in it is low and may be in the range of small deformations. It is known that here the behavior of the ground is elastic and linear, where $G$ does not undergo any significant degradation. In this sense, when the train runs on stiff soils, the geotechnical safety associated with the behavior of the ground is practically guaranteed and the calculation of the track displacements can be carried out with a simple and numerically highly efficient model such as the linear elastic model. However, when the speed of the train approaches the speed of propagation of Rayleigh waves in the ground, the deformations in the ground increase considerably causing a degradation of the stiffness of the ground that becomes totally relevant and that has an important influence both on the magnitude of the track displacements and on the value of the critical speed. In these cases, the accuracy and suitability of the linear elastic model is lower and non-linear cyclic models with degradations of the value of $\mathrm{G}$ are required to satisfy the strain conditions of the ground. In this respect, [13] has shown how the use of an Equivalent Linear approach (ELA) has led to reductions of between $10-20 \%$ in the value of the critical speed with respect to that obtained with the linear elastic model. Similar values have been found in the studies presented by [2,14].

The constitutive soil model known as the Hardening Soil Small Strain model (HSsmall) [15] is an advanced ground behavior model which takes into consideration the full degradation curve of $\mathrm{G}$, from the very small strains to the large strains associated with the failure of the soil. It forms part of the package of constitutive software models for commercial use such as Plaxis or Zsoil. Although it is a complex model, it is within the reach of all geotechnical engineers, making it a good tool of analysis for this type of cases. However, to the knowledge of the authors, it has never been experimentally validated in cases of critical speed in railway lines. For this reason and for the advance that this might lead to in the practice of geotechnical railway engineering, this study is presented with the aim of verifying whether the HSsmall model is a reliable tool for the prediction of displacements undergone by the track near critical speed and for the prediction of the critical speed. To do this, a numerical simulation of the famous Ledsgard case[1-4] has been performed, comparing the numerical results (with the HSsmall and Elastic Linear model) with those measured in reality.

\section{CASE STUDY OF LEDSGARD}

\subsection{Generalities}

The Ledsgard site is located $25 \mathrm{~km}$ to the south of Gothenburg. In the 1990s, excessive vibrations were detected all along the track and this led to an intense investigation on the geotechnical properties of this site [2]. Both the properties of the ground and those of the track have been shown in the many studies made of this case $[1-4,16]$ and the reader is advised to 
consult them. In this study, the data proposed by [2] have been used. These are summarized below, thus avoiding a reiterative description of the data found in the technical literature.

\subsection{Soil and track properties}

The geotechnical profile and a detail of the ballasted track is shown in fig. 1 .

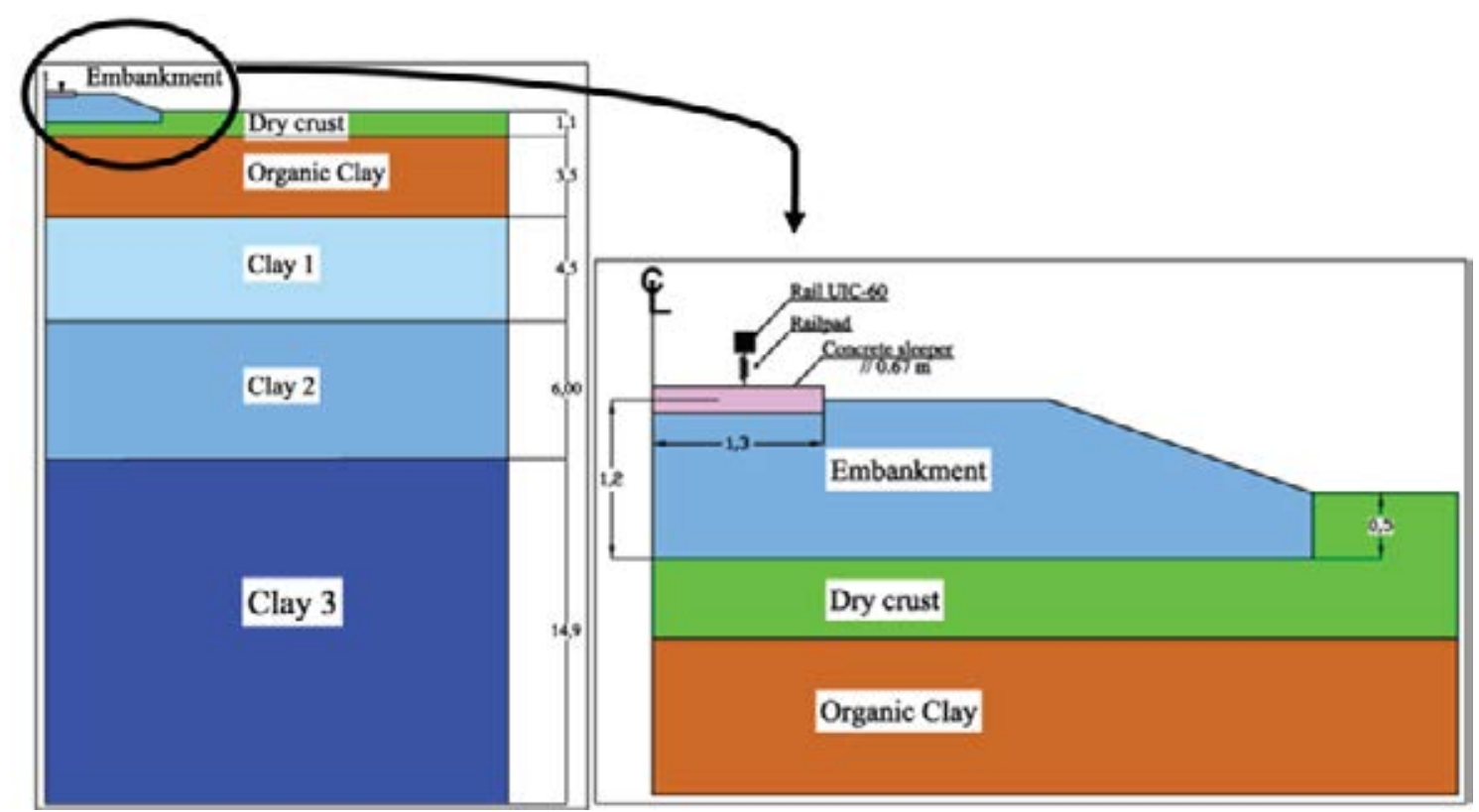

Figure 1: Soil (left) and ballasted track geometry (right) $[2]$.

The elastic properties of the ground are shown in Table 1, taken from the data provided by

\begin{tabular}{lcccc}
\hline Layer & Thickness $(\mathbf{m})$ & $\begin{array}{c}\text { Specific weight } \\
\left(\mathbf{k N} / \mathbf{m}^{3}\right)\end{array}$ & $\mathbf{G}_{\mathbf{0}}\left(\mathbf{k N} / \mathbf{m}^{\mathbf{2}}\right)$ & Poisson's ratio \\
\hline Embankment & 1.2 & 18.00 & $79.51 \cdot 10^{3}$ & 0.19 \\
Dry crust & 1.1 & 15.00 & $5.95 \cdot 10^{3}$ & 0.49 \\
Organic Clay & 3.5 & 12.60 & $2.17 \cdot 10^{3}$ & 0.49 \\
Clay 1 & 4.5 & 14.75 & $5.31 \cdot 10^{3}$ & 0.49 \\
Clay 2 & 6 & 14.75 & $11.18 \cdot 10^{3}$ & 0.49 \\
Clay 3 & 14.9 & 14.75 & $14.75 \cdot 10^{3}$ & 0.49 \\
\hline
\end{tabular}

Table 1: Soil elastic properties

As regards the degradation curves of $\mathrm{G}$ and the damping considered in the HSsmall model, these have the following equations [17] and are shown in fig.2:

$$
\begin{aligned}
G_{s} /_{G_{0}} & =\frac{1}{1+\frac{0.385 \cdot \gamma}{\gamma_{0.7}}} \\
\xi & =\frac{E_{D}}{4 \pi E_{s}}
\end{aligned}
$$




$$
\begin{gathered}
E_{D}=\frac{4 \cdot G_{0} \cdot \gamma_{0.7}}{0.385}\left(2 \cdot \gamma-\frac{\gamma}{1+\gamma_{0.7} / 0.385 \cdot \gamma}-\frac{2 \cdot \gamma_{0.7}}{0.385} \cdot \ln \left(1+\frac{0.385 \cdot \gamma}{\gamma_{0.7}}\right)\right) \\
E_{s}=\frac{G_{0} \cdot \gamma^{2}}{2+2 \cdot 0.385 \cdot \gamma / \gamma_{0.7}}
\end{gathered}
$$

where $\gamma_{0.7}$ is the shear strain for $\mathrm{G}_{\mathrm{s}} / \mathrm{G}_{0}=0.722$
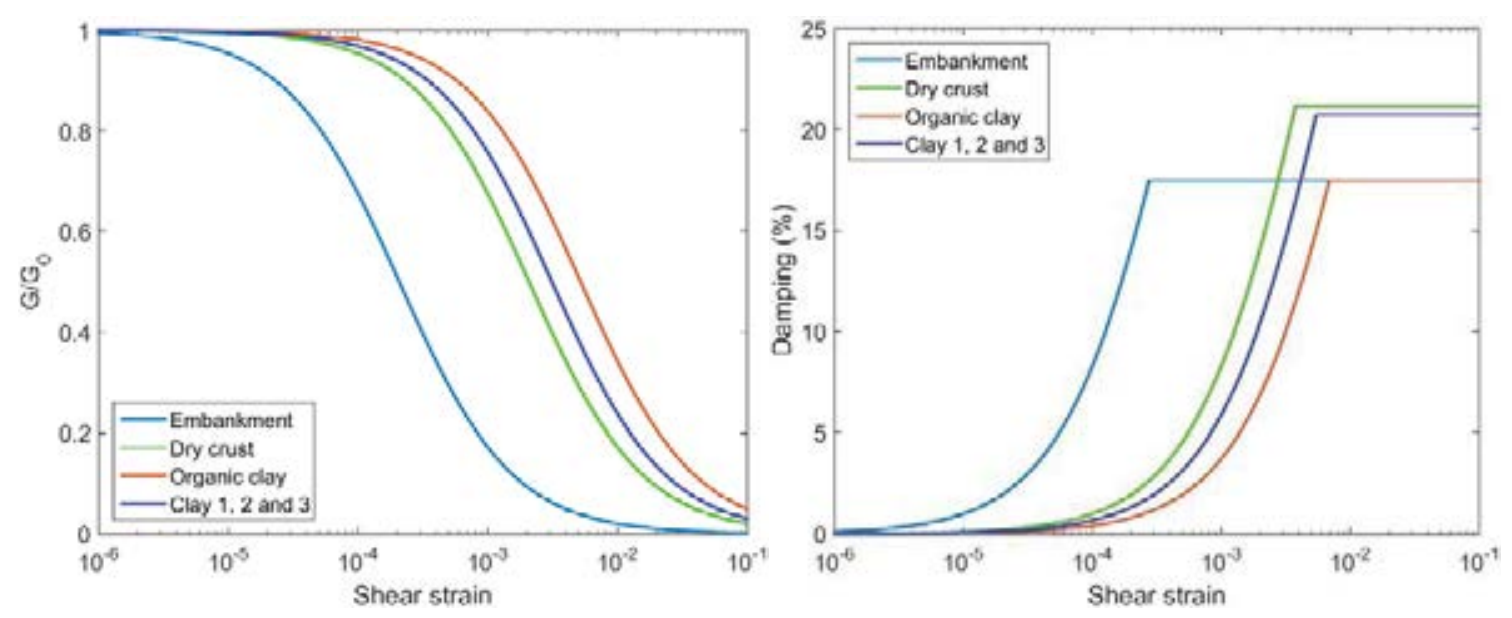

Figure 2: Shear modulus reduction (left) and damping ratio (right) (adapted [2])

Given that numerical simulations have also been made considering a linear elastic behavior of the ground, a Rayleigh damping has been considered. As regards the characteristics of the railway track, this corresponds to a ballasted track, with a rail type UIC60 which is seated on railpads of a stiffness of $250 \mathrm{kN} / \mathrm{mm}$. The sleepers have a length of $2.6 \mathrm{~m}$, a height of $0.2 \mathrm{~m}$ and are separated by $0.67 \mathrm{~m}$. Their elastic properties are mass density $2,500 \mathrm{~kg} / \mathrm{m} 3$, Young's modulus $3 \times 107 \mathrm{kN} / \mathrm{m} 2$ and Poisson's ratio 0.2. The ballast is included in the embankment shown in fig. 1, this being made up both of ballast and of gravels and sands [2]. The measurement of the track response during train passage was made with the X2000 train at different speeds. The geometry and axle load of this train are shown in fig. 3. The tests were performed in both directions, i.e. Northbound and Southbound but in this study only the Southbound direction is considered.

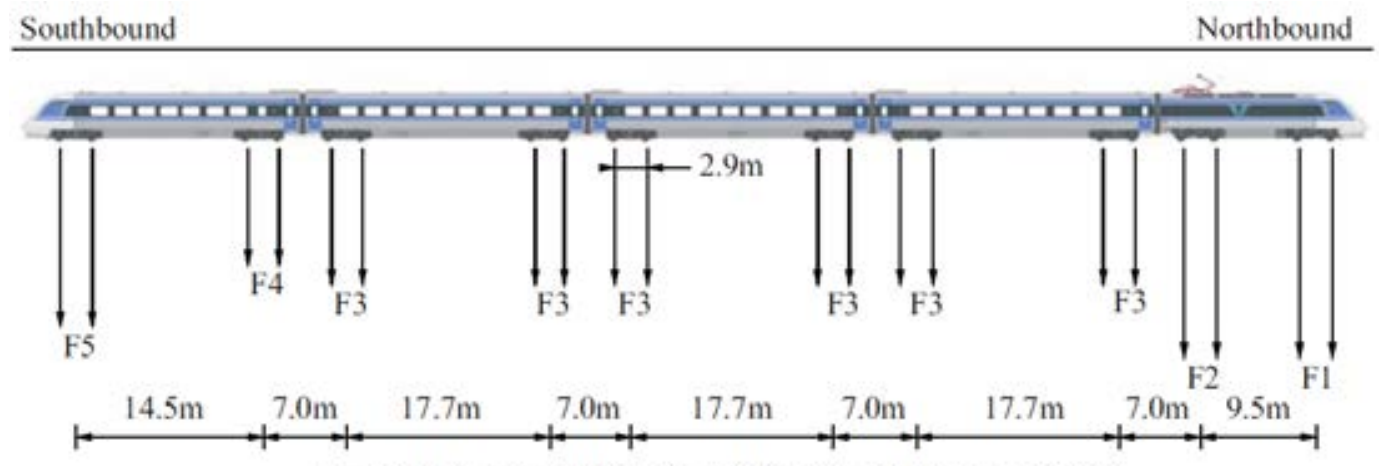

$\mathrm{FI}=181 \mathrm{kN}, \mathrm{F} 2=180 \mathrm{kN}, \mathrm{F} 3=122 \mathrm{kN}, \mathrm{F} 4=117 \mathrm{kN}, \mathrm{F} 5=160 \mathrm{kN}$

Figure 3: Geometry and axle load of X2000 train 


\section{EXPERIMENTAL VALIDATION}

\subsection{Numerical model}

To validate the HSsmall model experimentally, a dynamic 3D model formulated in the time domain has been developed in Plaxis software [15]. The geometry of the numerical model is shown in detail in fig. 4 and as can be seen it corresponds to a symmetric case, so that only half of it has been modeled. The dimensions of the model are 70x40x30 m in the longitudinal, horizontal and vertical directions respectively, which are values considered and experimentally validated in 3D models of finite elements formulated in the time domain similar to those used here [16,18-21]. The railpad is modeled as a linear spring, whereas the rail has been simulated as a beam, with the normalized properties of the UIC-60 type. The rest of the track components (sleeper, ballast and subballast) and ground were modeled using 3D solid elements.

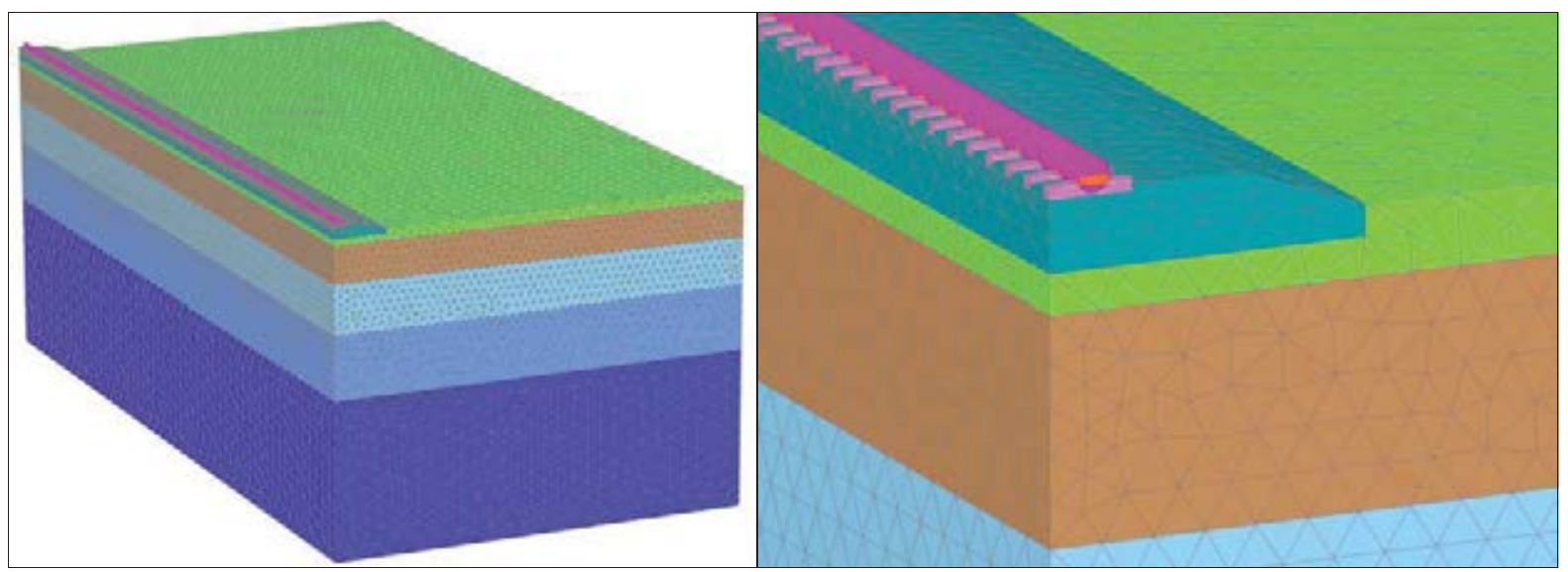

Figure 4: Numerical model: 3D view mode (left) and track detail (right)

The numerical model is made up of 370,181 elements and 523,961 nodes. Quadratic tetrahedral elements (10 node elements) are used for solid elements. The boundary conditions correspond to viscous dampers [15] in all boundaries except the plane of symmetry, where horizontal movements are impeded, and the ground surface, which is a free boundary.

As for the numerical modeling of the moving load, this has been applied using the equivalent nodal force method, in keeping with that described in [22] and the time step has been considered according to the criteria of Courant-Friedrichs-Lewy [16,22], with an implicit Newmark integration scheme, as shown below:

$$
C_{n}=\frac{\Delta t x C}{L_{\min }}<1
$$

where $\mathrm{Cn}$ is the Courant number, $\Delta \mathrm{t}$ is the time step, $\mathrm{C}$ is the moving load speed and Lmin is the distance between two adjacent loading nodes.

\subsection{Experimental validation}

Fig. 5 shows the experimental validation for four different train speeds: 70, 140, 180 and $204 \mathrm{~km} / \mathrm{h}$. As can be seen, the results obtained with the Linear Elastic model show relevant differences from those actually measured for the four speeds, these differences becoming 
more evident the higher the speed of the train. The Linear Elastic model tends to underestimate the dynamic response, and in quantitative terms it predicts only half of the actual displacement of the sleeper. These differences are important.

As for the results obtained by the HSsmall model, these are quite close to those actually measured for the four speeds studied. It is worth noting that the adjustment is quite acceptable and that it is more precise when the train speed is higher. In fact, for speeds of 180 and 204 $\mathrm{km} / \mathrm{h}$ the accuracy of the model is quite good while for the lower speeds (70 and $140 \mathrm{~km} / \mathrm{h}$ ), the results are also very close but with slightly greater differences than for the high speeds.

In this case, the critical speed is approximately $200 \mathrm{~km} / \mathrm{h}$. Around these speeds, the results of the HSsmall model are highly accurate, showing that the constitutive model is correctly reproducing the behavior of the different ground layers.

(a)

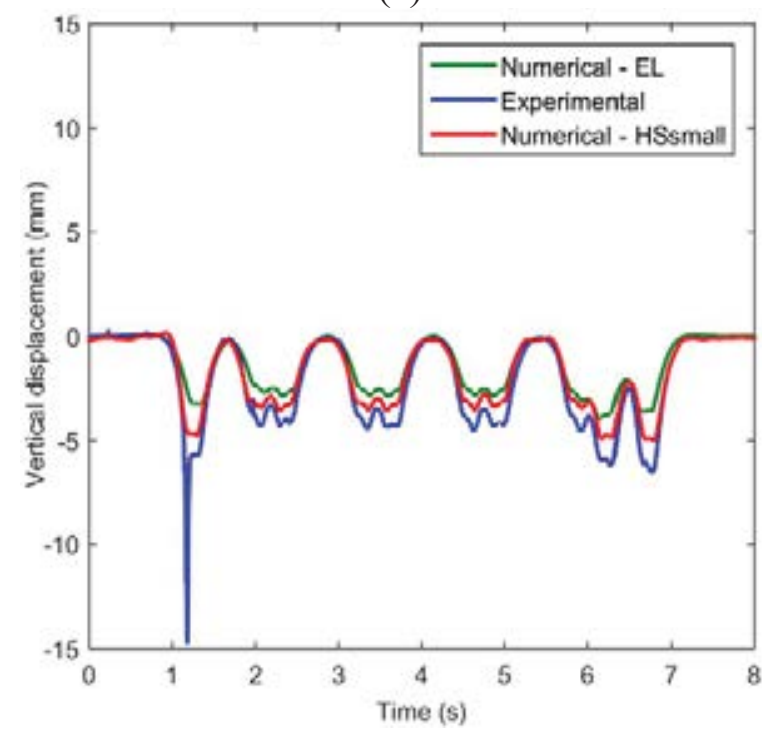

(c)

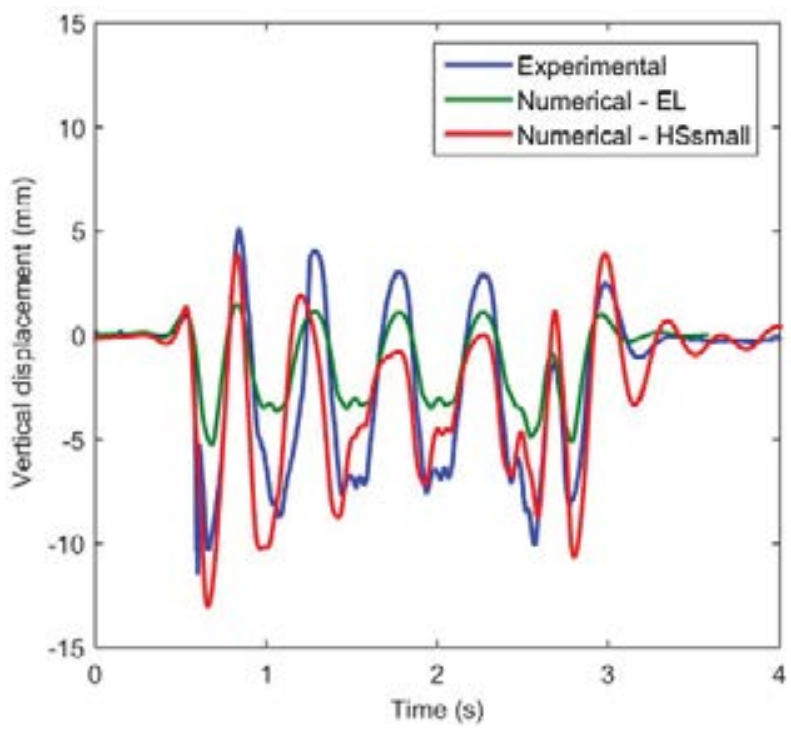

(b)

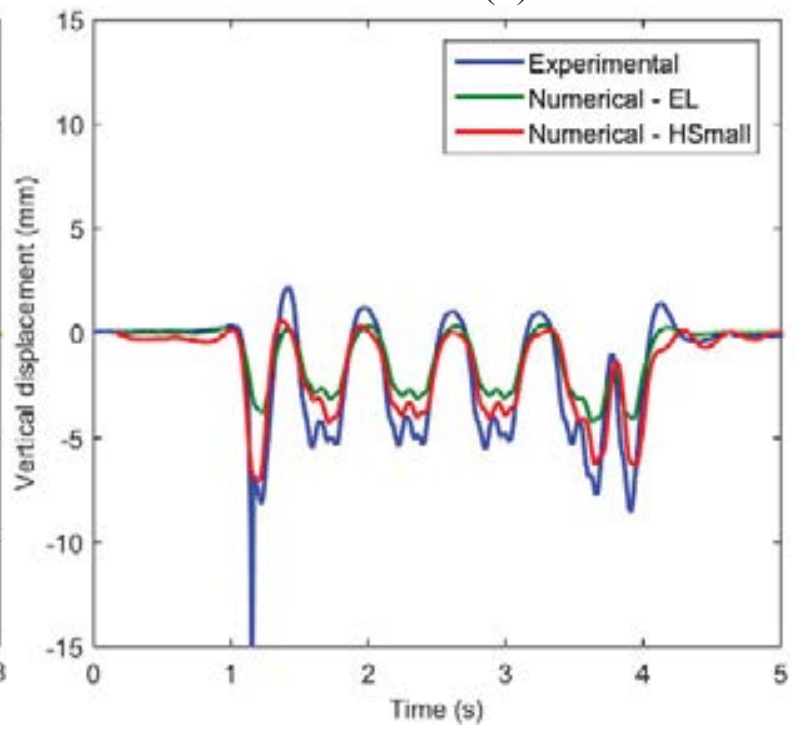

(d)

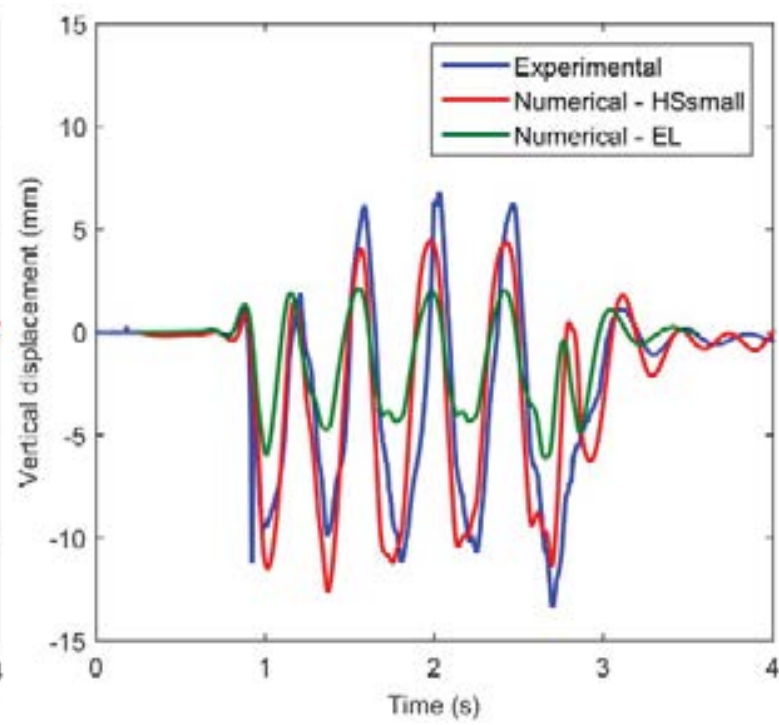

Figure 5: Measured and computed time histories of sleeper displacements for different train speeds (Southbound direction): (a) $\mathrm{V}=70 \mathrm{~km} / \mathrm{h}$; (b) $140 \mathrm{~km} / \mathrm{h}$; (c) $\mathrm{V}=180 \mathrm{~km} / \mathrm{h}$ and (d) $\mathrm{V}=204 \mathrm{~km} / \mathrm{h}$ 
Comparing the results between the HSsmall and LE models at low speeds, it can be observed that there is also an appreciable degradation of the stiffness of the ground layers, which the HSsmall model is also correctly simulating but which is obviously not being simulated correctly with the Linear Elastic model. This fact shows that the degradation of the stiffness of the ground is not only substantial near the critical speed, but that for speeds considerably lower than the critical speed there is also a significant degradation of the stiffness. It is likely that at low speeds the degradation of stiffness is more important in the structural layers of the track: ballast and subballast, while at speeds close to the critical speed, the degradation of the stiffness of the underlying ground plays a more important role than at low speeds.

\subsection{Critical speed for a single moving point load}

It has been considered of interest, once the HSsmall model has been experimentally validated, to calculate the critical speed of the Ledsgard case for a single moving point load. For this, the same numerical model has been considered, but with only one moving load. Two scenarios have been considered: Linear Elastic model and HSsmall model. The displacements of the sleeper and the Dynamic Amplification Factor (DAF) as a function of the speed of the load are shown in figure 6, where it can be seen how the HSsmall model gives a critical speed value of $47 \mathrm{~m} / \mathrm{s}$, while for the Linear Elastic model it is $53 \mathrm{~m} / \mathrm{s}$. Therefore, the use of the HSsmall model results in a critical speed which is $12 \%$ lower than that of the Linear Elastic model. These differences are relevant and demonstrate the suitability of the HSsmall model for predicting the critical speed of the train.

Regarding the displacements and the DAF, the HSsmall model yields higher values than the Linear Elastic model, so for the prediction of the track movements, the HSsmall model is more suitable, both for low speeds and those close to the critical speed, as shown above.

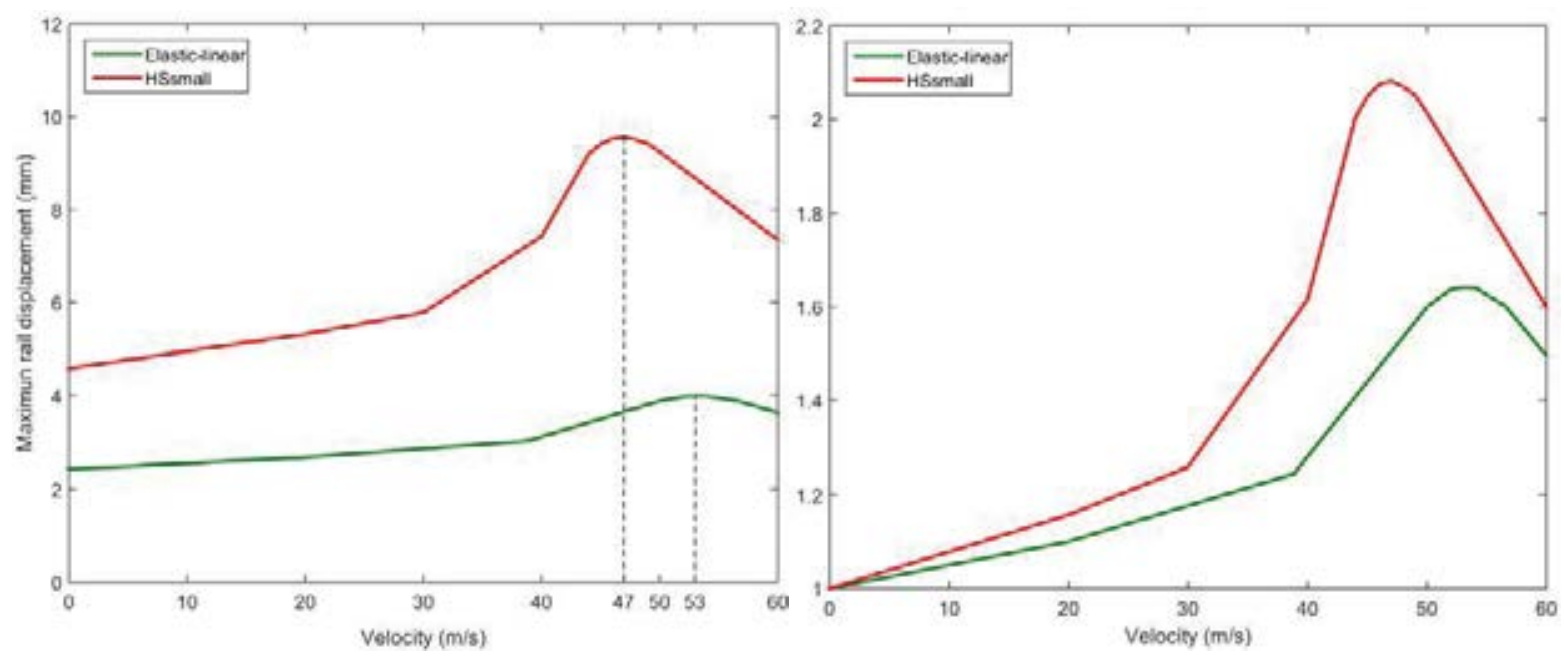

Figure 6: Sleeper displacements vs velocity (left); DAF in sleeper vs velocity (right)

\section{CONCLUSIONS}

This research has studied the applicability of the HSsmall constitutive model to the prediction of the movements of the track in railway lines. Numerical values have been obtained which are very close to those actually measured in the Ledsgard case, both for speeds close to the critical speed and for low speeds. In this respect, the HSsmall model has proven to be a reliable tool for the prediction of the movements of the track with a very acceptable level of accuracy. Moreover, it has been shown how the critical speed is $12 \%$ lower when analyzed 
with the HSsmall model with respect to that obtained by the Linear Elastic model. Hence, the use of the HSsmall model may be of greater use when in-depth studies are made of the critical speed.

\section{REFERENCES}

[1] L. Hall, Simulations and analyses of train-induced ground vibrations in finite element models. Soil Dynamics and Earthquake Engineering, 23, 403-413, 2003.

[2] P. Alves Costa, R. Calçada, A. Silva Cardoso,A. Bodare, Influence of soil non-linearity on the dynamic response of high-speed railway tracks. Soil Dynamics and Earthquake Engineering, 30(4), 221-235, 2010.

[3] C. Madshus and M. Kaynia, High-speed railway lines on soft ground: dynamic behaviour at critical train speed. Journal of Sound and Vibration, vol. 231(3), 689-701, 2000.

[4] H. Takemiya, Simulation of track-ground vibrations due to a high-speed train: the case of X-2000 at Ledsgard. Journal of Sound and Vibration, 261, 503-526, 2003.

[5] Alves Costa P, Colaço A, Calçada R, Cardoso AS. Critical speed of railway tracks. Detailed and simplified approaches. Transportation Geotechnics, 2, 30-46, 2015.

[6] Dieterman HA, Metrikine A. The equivalent stiffness of a half-space interacting with a beam. Critical velocities of a moving load along the beam. European Journal of mechanics a/solids, 15(1), 67-90, 1996.

[7] Dieterman HA, Metrikine A. Steady-state displacements of a beam on an elastic halfspace due to a uniformly moving constant load. European Journal of mechanics a/solids, 16(2), 295-306, 1997.

[8] Sheng X, Jones C, Thompson D. A theoretical study on the influence of the track on train-induced ground vibration. Journal of Sound and Vibration, 272, 909-36, 2004.

[9] Alves Costa P, Lopes P, Silva Cardoso A. Soil shakedown analysis of slab railway tracks: numerical approach and parametric study. Transportation Geotechnics, 16, 8596, 2018.

[10] Madshus C, Lacasse S, Kaynia A, Harvik L. Geodynamic challenges in high speed railway projects. In: GeoTrans 2004 - geotechnical engineering for transportation projects, ASCE; 192-215. Los Angeles, 2004.

[11] Kaynia M, Madshus C, Zackrisson P. Ground vibrations from high-speed trains: prediction and countermeasure. Journal of Geotechnical Geoenvironmental Engineering 126(6), 531-537, 2000.

[12] Krylov V. Generation of ground vibrations by superfast trains. Applied Acoustics, 44, 149-64, 1995.

[13] Dong, K., Connolly, D.P., Laghrouche, O., Woodward, P.K., Alves Costa, P. Non-linear soil behaviour on high speed rail lines. Computers and Geotechnics, 112, 302-318, 2019.

[14] TShih, J.Y., Thompson, D.J., Zervos, A. The influence of soil nonlinear properties on the track/ground vibration induced by trains running on soft ground. Transportation Geotechnics, 11, 1-16, 2017. 
[15] Brinkgreve, R.B.J., Kumarswamy, S., Swolfs, W.M., Zampich, L., Ragi Manoj, N. 2019. Plaxis 2019 User Manuals. Plaxis bv, Delft.

[16] Abu Sayeed, Md., Shahin, M.A. Three-dimensional numerical modelling of ballasted railway track foundations for high-speed trains with special reference to critical speed. Transportation Geotechnics, 6, 55-65, 2016.

[17] Brinkgreve RBJ, Kappert MH, Bonnier PG. Hysteretic damping in a small-strain stiffness model. Numerical Models in Geomechanics-NUMOG X-Pande \& Pietruszczak (eds), 2007 Taylor\&Francis Group, London, ISBN 978-0-415-44027-1

[18] El Kacimi, A., Woodward, P.K., Laghrouche, O., Medero, G. Time domain 3D finite element modelling of train-induced vibration at high speed. Computers and Structures, 118, 66-73, 2013.

[19] Fernández Ruiz, J., Alves Costa, P., Calçada, R., Medina Rodríguez, L.E. and Colaço, A. Study of ground vibrations induced by railway traffic in a 3D FEM model formulated in the time domain: experimental validation. Structure and Infrastructure Engineering 13(5), 652-664, 2017.

[20] Fernández-Ruiz, J., Medina Rodríguez, L.E., Alves Costa, P., Martínez-Díaz, M. Benchmarking of two three-dimensional numerical models in time/space domain to predict railway-induced ground vibrations. Earthquake Engineering and Engineering Vibration, 20, 245-256, 2021.

[21] Fernández-Ruiz J, Medina Rodríguez LE, Costa PA. Use of Tyre-Derived Aggregate as Backfill Material for Wave Barriers to Mitigate Railway-Induced Ground Vibrations. International Journal of Environmental Research and Public Health, 17(24), 9191, 2020 .

[22] Galavi V, Brinkgreve RBJ. Finite element modelling of geotechnical structures subjected to moving loads. In: Hicks et al., editors. VIII ECNUMGE - numerical methods in geotechnical engineering. Delft, Netherlands: Taylor \& Francis - Balkema; 235-40, 2014. 